ESCENA

Publicación semestral. ISSN 2215-4906

Volumen 78 - Número 2

Enero - Junio 2019

\title{
Diente de León
}

\author{
Luz Elena Muñoz Salazar
}

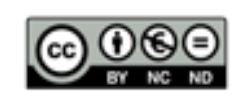

Esta obra está bajo una licencia Creative Commons Reconocimiento-No comercial-Sin Obra Derivada 
Obra artística

\title{
Diente de León
}

\author{
Luz Elena Muñoz Salazar ${ }^{1}$ \\ Directora teatral independiente \\ Cali Colombia
}

Recibido: 4 de julio del 2018 Aprobado: 7 de octubre del 2018

Las repetidas Lilia y Lidia están escondidas en un cuarto de ropa pequeñísimo que se comunica con la cocina, esperan al Hombre Literalmente Invisible y a la Madre, él no regresa nunca, ella muere como gallina ciega.

1 Directora teatral independiente. Ganadora de la convocatoria de Creación Artística 2018; lanzada por el Instituto de Patrimonio y Cultura de Cartagena de Indias IPCC en Colombia. Máster en Neuropsicología y Educación de la Universidad Internacional de la Rioja (UNIR). Correo electrónico: elenasin2@hotmail.com

ESCENA. Revista de las artes, 2019, Vol. 78, Núm. 2 (enero-junio), pp. 178-188 


\section{Personajes:}

Lilia y Lidia.

Hombre Literalmente Invisible.

Madre.

\section{ESCENA I. EL ARMARIO}

Están en un cuarto de ropa pequeñisimo que se comunica con la cocina a través de una ventanita azul de alas, hay una puerta que no se ve nunca y da al incierto exterior.

LIDIA. Somos almohadas en la parte interior del armario de madera blanco, a través de los calados se va durmiendo el día.

LILIA $\quad$ No me gusta, no quiero estar aquí.

LIDIA ¿Qué es redondo, blanco y frío?

LILIA ¿La luna?

LIDIA No. Da ganas de comerlo.

LILIA ¿Una arepa con mantequilla?

LIDIA Tonta... el queso.

LILIA Ah sí... ¿pero? no es tan redondo (Silencio). Dicen que a las vacas de los papás de Anna les da pena de los hombres y no dan leche. Pero a mí se me hace que ellas sí dan leche y esos montañeros se la toman toda.

LIDIA Son cuentos. Te van a arrancar la lengua si te escuchan hablando bobadas.

LIIA (Como sin lengua) Mira no tengo lengua. ¿Por qué estamos aquí?

LIDIA Porque... estamos jugando al escondite.

LILIA Nadie nos busca. Yo buscaré.

LIDIA No.

LILIA Sí. 
LIDIA Ven aquí.

LILIA Nada por aquí, por aquí tampoco. Deben estar afuera.

LIDIA No, no, no. Ven, te encontrarán.

LILIA Están en la carretera.

LIDIA Cállate, cállate. ¿Qué es pequeñísimo, salta por todas partes y vive en nuestro perro?

LILIA En el carpati hay personas con chuspas y no llueve.

LIDIA Ellos también juegan al escondite.

LILIA Tan tonticos, así los descubre cualquiera, no ve que se les ven los pies. La pulga. Me toca a mí. ¿Quién es tonto y no habla?

LIDIA ¿Hasta cuándo tendré que repetirte que el papá de Anna no es tonto?

LILIA Es tonta una persona cuando permite que los hombres se tomen la leche de sus vacas y se tomen a su mujer y a su hija.

LIDIA Ellas no son leche.

LILIA Pero dan leche como las vacas, yo lo vi. A las mujeres en el puesto de salud les salía leche de las tetas. A mí no me sale ¿y a ti?

LIDIA Solo les sale a las mujeres barrigonas.

LILIA Pajuda, las mujeres barrigonas estallan. Ayer dos mujeres barrigonas estallaron en la caseta. Vivían antes de llegar al puente, seguro caminaron mucho y cuando llegaron a la caseta estallaron; o quizá estaban muy felices. El profe dice que está a punto de estallar de felicidad. Es como destornillarse de risa, cuando uno se tira el primer pedito hay que parar, sino sería fatal.

LIDIA Sos una flacucha pedorra. Uno no sabe si estallarás de pedos o de risa... pedorra.

LILIA Me gustaría (Mirando por una ventanita que da a la cocina), ¿no te pasa que antes de estallar de risa se te viene la soledad y te entra la llorona? Prefiero estallar que sentir eso, como ahora.

LIDIA (Canta)

"No sé qué tienen las flores llorona 
Las flores del campo santo.

Que cuando las mueve el viento llorona,

Parece que están llorando"2.

LILIA Que aparezca papi, despertamos a mamá y nos vamos para siempre (silencio). Tenías razón, la gente por dentro tiene colores, como las plantas (Silencio largo). A mami se le está saliendo la pintura.

(Lidia retira a Lilia abruptamente de la ventanita e introduce por ella su cabeza, mira petrificada el cuerpo sobre el piso de la Madre derramada con un chiro ${ }^{3}$ blanco en el rostro, el Hombre Literalmente Invisible piensa algo invisible y permanece sentado en la banca cantando fragmentos de Alma Mía solamente en la cabeza de Lidia, la ventanita se cierra de golpe).

LIDIA Vamos a dormir.

LILIA Vamos a jugar.

LIDIA Vamos a dormir y punto.

LLIA _Final o seguido?

LIDIA Final.

LILIA Aquí no se termina esta historia.

LIDIA Esto no es una historia.

LILIA Te contaré un sueño, me da miedo, te lo cuento para que no pase, mamá dice que si cuentas los sueños feos no se cumplen.

LIDIA Los sueños significan lo contrario. Cuéntalo, después dormiremos.

LLIA $\quad$ Y no despertaremos nunca.

LIDIA ¿Por qué?

2 "Llorona", canción de Chavela Vargas (1919-2012).

3 Trapo.

4 “Alma mía”, canción de Julio Jaramillo (1935-1978).

ESCENA. Revista de las artes, 2019, Vol. 78, Núm. 2 (enero-junio), pp. 178-188 
LLIA Porque así no nos dará hambre. Tengo hambre.

LIDIA Prepararé tortas de sangre.

LILIA A vos no te quedan ricas. Cuando siento tus tortas blanditas y aceitudas... me da ganas de vomitar.

En el sueño yo estaba aun con el uniforme, de rodillas preparándome para vomitar y vos estabas detrás de mí con la capita blanca y la cara cubierta con un chiro también blanco. Yo no te estaba mirando, porque estabas detrás de mí. No sé uno como es que hace en los sueños pa' ver lo que no está viendo. El caso es que estabas parada y te apoyabas en el riflecito de balines con que papá espanta las chuchas del gallinero. Era como cuando jugamos a la gallina ciega. Me sentí aterrada, porque parecías sonámbula, y cuando sonámbuleas rompes los vasos o te orinas.

LIDIA ¿Ya acabaste?

LLIA No. Empezamos a jugar a la gallina...

LIDIA (Interrumpiéndola) Duérmete ya.

LILA Pero es que el sueño no termina allí...

LIDIA No importa, duérmete y no despiertes nunca más. Para que no tengas más sueños y para que yo no me orine y tú no vomites, y para que no tengamos hambre. Duérmete de una puta vez.

LILIA Boquisucia. Vos nunca jugás conmigo.

LIDIA Vos callate.

LILIA Vos no me callés.

LIDIA Vos te callás o digo que no te pusiste calzones esta semana porque los tenés todos sucios.

LILIA ¿Sí? Yo puedo contar que en el recreo pistiás a los niños cuando van al baño.

LIDIA Callate, callate, callate.

LILIA (Abrazándola) Tranquila. Yo los he visto también, son raros, hacen chichi parados. 
LIDIA Debiste contar ese sueño antes. Era con mami con quien otros jugaban a la gallina ciega.

LILIA Era solo un sueño tontica.

\section{ESCENA II. SILENCIO POR FAVOR}

Lidia entra por la ventanita a la cocina, el Hombre Literalmente Invisible y la Madre están sentados a la mesa, muertos literalmente de hambre. Lidia prepara la comida para Lilia. El piso esta embarrado y los patos lloran de frío con un llanto infantil en un rincón, hay un fuerte olor a su excremento.

LIDIA: $\quad$ La fotosíntesis es el proceso mediante el cual las plantas elaboran su propio alimento, Simón Bolívar libertador nació en Cartagena y en Caracas murió, el río más largo y caudaloso de Colombia es el Magdalena y el más ancho y profundo es el Amazonas, el orden de los factores no altera el producto, este producto no es igual al producto interno bruto, se es bruto cuando no se sabe escribir ni leer, leer para el próximo lunes El coronel no tiene quien le escriba, vaca se escribe con v chiquita, la b grande es pa' los burros y las bobadas, es una bobada escribir con h porque no suena, que no suene ni una mosca en el examen porque lo anulo... anular es desaparecer, abolir, invalidar, cancelar, apagar, evaporar, desvanecer, esfumar, borrar, concluir, cerrar, dejar de correr, dejar de ser. Odio correr.

Que se calle el maestro por favor. Me ha enseñado de todo ¿Y qué? cómo decirle a ella que tiene que correr, que tiene que irse, que no pregunte más, que esto no es un juego, que hable bajito por favor. Que no se callen estas canciones que hacen que mi padre no sea invisible, que no se callen las canciones tristes y las felices. No quiero escucharme (Silencio largo). Odio correr. No voy a correr. Sí, soy la gordita perezosa, pasé educación física porque el profe dice que hay enfermedades que no se curan con la escuela. No me gusta correr y no espero tener hijos. Tiene hambre, tiene que correr y yo no voy a correr por ella ¿usted correría en estas circunstancias? Ahora no sé qué haría afuera. Me gusta caminar por el desecho antes de la quebrada. Un día fuimos a un intercolegiado de fútbol de niñas a Peñas Blancas y me tocó de portera del equipo, porque los porteros corren menos que el resto de jugadores, a los diez minutos del primer tiempo ya estaba fuera del juego; le pegué una patada de frente al balón y se me enchichonó el dedo gordo, 
me tocó quitarme el zapato para regresar a casa. Ella me tomó por la cintura y se vino todo el camino haciendo preguntas. Prometimos que no volveríamos a patear nada en nuestras vidas, porque patear algo, es patearse un poco uno mismo. Tomamos el desecho y nos acostamos en la última vuelta antes de la quebrada, porque nos gusta soplar dientes de león... no me deja nunca. Soy demasiado lenta, si corro con ella nos atraparían rápidamente. (Termina de poner el comedor, cubre con el gorrito de la licuadora el rostro de la Madre, para el Hombre Literalmente Invisible usa el sombrero de espantapájaros y por último se mete a la nevera).

\section{ESCENA III. DERRAMAR}

VOZ DE LIDIA (Se escucha una eufonía de pedos mientras canta)

"No sé qué tienen las flores Ilorona

Las flores del campo santo.

Que cuando las mueve el viento llorona,

Parece que están llorando."

(Lilia mira la cocina por la ventanita y dice algo inaudible. El cuerpo de la Madre se derrama de múltiples formas con un chiro blanco en el rostro, durante el tiempo que dura la canción. Lilia es retirada abruptamente de la ventanita, Lidia introduce por ella su cabeza, mira petrificada el cuerpo de la Madre que está ahora derramado sobre el piso, el Hombre Literalmente Invisible piensa algo invisible y permanece sentado en la banca cantando fragmentos de Alma Mía. Se oye un sonido que destiempla los dientes, el sonido está solamente en la cabeza de Lidia, la ventanita se cierra de golpe).

La voz del Hombre Literalmente Invisible persiste y se va apagando.

MADRE Solo sabía la dirección o mejor dicho, tenía los números escritos en un papel con forma de barco. Nos conocimos en el velorio de un familiar.

Mi padre hacía una zanja alrededor de la casa, como a dos metros; por la noche prendía candela en ella, para que no entraran los animales. Algunas noches soñé un cuerpo de uno, sobre mi cuerpo, me aterró la mirada luminosa y la respiración violenta de la fiera en la oscuridad. 
HOMBRE (Preparando un tintico para los dos). Nos conocimos en el velorio de un famiLITERALMENTE liar suyo, dijo que había llegado hasta allí en un barquito de papel.

INVISIBLE

Dormí con zapatos durante muchas noches sin que mis padres lo supieran, tenía la repentina sensación de que un día tendríamos que salir corriendo y es difícil correr sobre la tierra, cuando se está descalzo. Nuestras vidas llegaban hasta el río, así que hice barquitos de papel porque no bastaba con correr.

O

"Amor mío tu rostro querido no sabe guardar secretos de amor; ya me dijo que estoy en la gloria de tu intimidad. No hace falta decir que me quieres, no me vuelvas loco con esa verdad; no lo digas, no me hagas que llore de felicidad. Cuánta envidia se va a despertar, cuántos ojos nos van a mirar; la alegría de todas mis horas, Prefiero guardarlas en la intimidad. Olvidaba decir que te quiero. Con todas las fuerzas que el alma me da; quien no ha

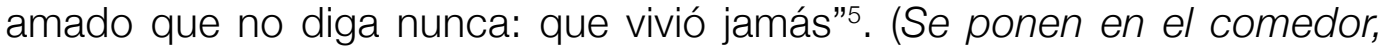
permanecen hasta el final de la pieza en este espacio). Soy jardinero. En la casa donde trabajo están necesitando alguien que planche, y como su tía me contó que usted necesitaba algo pa' sostenerse...

MADRE Es que yo no sé manejar eso.

HOMBRE No es problema, puede aprender, intentemos con una plancha así sea dañaLITERALMENTE da. Con la picardía de enseñarle a planchar nos fuimos haciendo íntimos... INVISIBLE Vivimos ahora en este jardín donde se respira claro, las niñas soplan dientes de león y se puede escuchar a los patos reír. Deseo tirarme al acantilado.

MADRE ¿Qué es eso?

HOMBRE "Le rogaban que no les mandase ir al acantilado de gran profundidad. Había LITERALMENTE allí un hato de muchos puercos que pacían en el monte; y le rogaron que los INVISIBLE dejase entrar en ellos; y los dejó"6. No sé lo que es, pero, prefiero ir allá antes que estar con esos cerdos...

MADRE Cómo es de rica la carne de esos animales (silencio incómodo). Los perros ladraron toda la noche, pensamos que podían estarlo buscando en la casa de los patrones, él se levantó con el riflecito de balines, era luna llena, lo vi por la ventana. Bajó bordeando el camino de flores amarillas y no le vi más hasta la

${ }^{5}$ Amor Mío. Álvaro Carrillo.

${ }^{6}$ Lucas 8: 31-32.

ESCENA. Revista de las artes, 2019, Vol. 78, Núm. 2 (enero-junio), pp. 178-188 
tardecita, cuando el profe de Español, no sé cómo, bajó hasta la casa, a avisar que parecía que lo habían encontrado en la curva de los dientes de león, antes de llegar a la quebrada. Metí a las niñas en el armario y subí para traerlo. No me lo permitieron. Él regresó a casa ya cuando los pájaros se lo habían comido y se sentó ahí a cantar.

HOMBRE Andrés, el profe de Español se apagó porque alguien lo vio entrar a nuestra LITERALMENTE casa. Esa tarde él había regresado por los libros a la caseta, unas mujeres INVISIBLE barrigonas estaban en la entrada y cuando los hombres vinieron por él, ellas dijeron que no lo habían visto, y ahí mismo las estallaron. Él sabía que lo estaban buscando, se subió al techo y trepó la reja. Lo escondimos aquí, era un buen tipo y si no lo fuera... quizá también lo habríamos escondido. Alguien en el puesto de salud les dijo a los hombres que lo habían visto entrar a esta casa y vinieron a buscarlo, reblujaron ${ }^{7}$ por todas partes, pero no buscaron en la nevera, que está dañada desde hace rato. Por la nochecita se fue.

Los perros ladraron hasta el amanecer, pensamos que podían estarlo buscando en la casa de los patrones, tomé el riflecito de balines y fui a mirar... eran los hombres, habían venido por mí. Por alcahueta -dijeron-. (A los espectadores) ¿Tengo balas de VERDAD en mi rifle? -pregunté- (silencio) pero nadies contestó. Andrés se dio cuenta que ellos me habían ruñido hasta los güesos, bajó a avisar a la casa y después de eso se apagó. (Canta fragmentos de Carnaval de la Vida ${ }^{8}$, luego hay un silencio incómodo larguísimo). Para cuando regresé, mi esposa era una gallina... ciega. ¿Y ellas? Se me va la muerte queriendo morir otra vez.

\section{ESCENA IV. ¿POR QUÉ NO RÍEN LOS PATOS?}

(Lilia entra a la cocina por la ventanita, las brasas hacen una penumbra calurosa y el excremento de los patos que lloran con un llanto infantil en el rincón es ahora intolerable).

LILIA A ver cochinos, a cagar al monte. Tiras, vengan pa'ca, siticos. (Hace maniobras con una olla en el fogón, vacía agua en la ponchera y uno a uno coloca a los patos en ella para quitarles el barro de una manera amorosísima. Silencio largo. Toca repetidamente la puerta de la nevera). ¿Quién falta por comer?

\footnotetext{
7 La forma normalizada es rebrujar: esculcar, escudriñar (Colombia).

8 Julio Jaramillo.
} 
LIDIA Solo vos.

LILIA Es mucho, ¿querés un poquito?

LIDIA No tengo hambre.

LILIA Calenté un poquito de agua ¿Tenés frío?

LIDIA No.

LIIIA Salí un momentico.

LIDIA Dejáme dormir.

LILIA Ya salió el sol y los patos estaban llorando.

LIDIA ¿Te despertaron? Echalos pa'l patio.

LILIA Como que hice un daño.

LIDIA (Saliendo de la nevera) ¿Qué paso?

LILIA (Toma de la mano a Lidia, se paran frente a la ponchera9). Mirá, no se quieren despertar, ya no lloran, tampoco se ríen (Silencio largo).

LIDIA Tranquila, nadie se va a enterar (a los espectadores) de lo que ocurrió aquí. (Siembra los patos en una matera mientras tararea la canción, de la cual solo se escucha el siguiente verso) "Nadie nos oye, el viento se ha quedado dormido entre las ramas, todo es en derredor silencio y calma. Pero calla, sí, pero calla"10. Lo bueno de ser jardinero es que todo lo que siembras nace.

LILIA (Mirando el comedor). Entonces, deberíamos sembrarlos también. (Abren la puerta del patio, el sol sonríe en sus rostros, el viento trae consigo una brisa de dientes de león, salen tomadas de la mano riendo, mientras el Hombre Literalmente Invisible y la Madre bailan, la luz va desvaneciéndolos). Deja de cantar canciones invisibles

9 Recipiente circular de plástico o de metal con diferentes uso; las grandes las utilizan para lavar la ropa, las pequeñas para lavarse las manos o la cara.

10 "Sí pero calla", canción de Hermanas Mendoza Sangurima.

ESCENA. Revista de las artes, 2019, Vol. 78, Núm. 2 (enero-junio), pp. 178-188 